\title{
Network pharmacology analysis and experimental study strategy reveals the potential mechanism of puerarin against rotavirus
}

\author{
Ting Chen ${ }^{1 \#}$, Yujie Lin ${ }^{2 \#}$, Zhiqun Cao ${ }^{1,3}$, Ye Xue ${ }^{1}$, Wei Wang ${ }^{4}$, Xiaoyan Wang ${ }^{5}$ \\ ${ }^{1}$ The First Clinical Medical College of Shandong University of Traditional Chinese Medicine, Jinan, China; ${ }^{2}$ Department of Traditional Chinese \\ Medicine, Sun Yat-sen Memorial Hospital Affiliated to Sun Yat-sen University, Guangzhou, China; ${ }^{3}$ Department of Digestive Endoscopy, Affiliated \\ Hospital of Shandong University of traditional Chinese Medicine, Jinan, China; ${ }^{4}$ Department of Spleen and Stomach Diseases, Affiliated Hospital of \\ Shandong University of Traditional Chinese Medicine, Jinan, China; ${ }^{5}$ College of Traditional Chinese Medicine, Shandong University of Traditional \\ Chinese Medicine, Jinan, China \\ Contributions: (I) Conception and design: T Chen, Y Lin, X Wang; (II) Administrative support: Z Cao; (III) Provision of study materials: Z Cao; (IV) \\ Collection and assembly of data: W Wei; (V) Data analysis and interpretation: Y Xue; (VI) Manuscript writing: All authors; (VII) Final approval of \\ manuscript: All authors. \\ "These authors contributed equally to this work. \\ Correspondence to: Xiaoyan Wang. College of Traditional Chinese Medicine, Shandong University of Traditional Chinese Medicine, Jinan 250355, \\ China. Email: qingdai1982@126.com.
}

Background: This study aimed to explore the underlying mechanism of puerarin against rotavirus (RV), based on network pharmacology analysis and experimental study in vitro.

Methods: The cytopathic effect inhibition assay with different concentrations of puerarin at different times of infection in vitro was applied to evaluate the effect of puerarin against human RV G1P[8] Wa strain (HRV Wa). Subsequently, the potential targets of puerarin and RV-related genes were obtained from online databases. Kyoto Encyclopedia of Genes and Genomes (KEGG) pathway enrichment analyses of the major target genes were also performed. Furthermore, the major targets and signaling pathway related to RV infection were verified at the molecular level via Western blot, quantitative real-time reverse transcription PCR (RT-qPCR), and Enzyme-linked immunosorbent assay (ELISA) tests.

Results: Our results suggest that puerarin had a certain inhibitory effect on viral replication and proliferation. The network pharmacology analysis showed that a total of 436 puerarin corresponding target and 497 RV-related targets were acquired from the online databases. The core targets of puerarin against RV, such as Toll-like receptor 4 (TLR4), tumor necrosis factor (TNF), and caspase 3 (CASP3), were identified from the protein-protein interaction (PPI) network. The KEGG analysis indicated that the TLR signaling pathway was one of the crucial mechanisms of puerarin against RV. In particular, puerarin could inhibit the expression of key factors of the TLR4/nuclear factor kappa-B (NF-kB) signaling pathway in HRV-infected Caco-2 cells and regulate the levels of cellular inflammatory factors.

Conclusions: Based on the network pharmacology analysis and experimental study, the study showed that puerarin not only had an anti-RV effect, but could also modulate the inflammatory response induced by RV infection via the TLR4/NF- $\mathrm{BB}$ signaling pathway. This study reveals the potential of puerarin in the treatment of RV infection, suggesting that it might be a promising therapeutic agent.

Keywords: Human RV G1P[8] Wa strain (HRV Wa); puerarin; network pharmacology; Toll-like receptor 4/ nuclear factor kappa-B signaling pathway (TLR4/NF- $\mathrm{BB}$ signaling pathway)

Submitted Oct 26, 2021. Accepted for publication Dec 24, 2021.

doi: $10.21037 / \mathrm{atm}-21-6089$

View this article at: https://dx.doi.org/10.21037/atm-21-6089 


\section{Introduction}

Rotavirus (RV) is a double-stranded unenveloped RNA virus of the Reoviridae family, with a diameter of $75 \mathrm{~nm}$ and a "wheel-like" appearance. The RV genome is composed of 11 double-stranded RNA segments, encoding six structural proteins and six non-structural proteins (1). RV is transmitted via the fecal-oral route, which can attack mature intestinal epithelial cells and destroy the complex intestinal ecosystem. The intestinal epithelium is shed and destroyed, and the migration of RV from the crypts to the cilia is accelerated, resulting in a temporary loss of intestinal absorption capacity, and severe watery diarrhea occurs when RV is colonized in the intestine (2). Although its infection rate dropped after vaccination began, $\mathrm{RV}$ is still common worldwide and is considered to be one of the major pathogens causing intestinal inflammation in infants and many young children $(3,4)$. Every year, over 200 million children younger than 5 years old are infected with $\mathrm{RV}$, resulting in more than 200,000 deaths worldwide (5). At present, RV infectioninduced acute gastroenteritis is a common cause of pediatric hospitalization in developed and developing countries, and poses a huge economic burden $(6,7)$. There is currently no specific treatment for RV. The main treatment for RVinduced gastroenteritis is to prevent or correct severe dehydration and metabolic disorders through rehydration, electrolyte supplementation, and nutritional support (8). In addition, probiotics, zinc, and other biological compounds can also relieve clinical symptoms such as diarrhea $(9,10)$.

Chinese herbs have advantages in the treatment of viral infectious diseases. The root of Pueraria lobata (Willd) Ohwi is a kind of medicinal and edible Chinese herb. It was first recorded in Shennong's Classic of Materia Medica about 1800 years ago, as a medicinal herb that can strengthen the Yang Qi (energy) of the spleen and stomach, and relieve diarrhea. The root of Pueraria lobata is often used in the clinical treatment of RV gastroenteritis. Puerarin, an isoflavone compound, is the main component of the root of Pueraria lobata. It has a variety of pharmacological properties, including anti-inflammatory (11), antioxidative (12), antitumor, and circulation-improving effects $(13,14)$. In addition, studies have shown that puerarin has antiviral effects, including epidemic diarrhea viruses and the influenza virus $(15,16)$. However, there remains a lack of relevant reports demonstrating the antiviral effect of puerarin against RV.

Network pharmacology is a novel research method that integrates the general ideas of systems biology and computer technology. The systematic and collaborative characteristics of network pharmacology are similar to the theory of traditional Chinese medicine (17). Due to the multi-target and multi-channel characteristics of Chinese herbal medicine, its mechanism of action is difficult to fully explain. Network pharmacology provides new ideas and scientific support for the research of complex systems of Chinese herbal medicine, and has been widely used in the discovery of active compounds, interpretation of the overall mechanism of action, as well as analysis of drug combination and prescription compatibility. Puerarin has a variety of therapeutic effects, and there are many literatures on the mechanism of puerarin action based on network pharmacology. However, the anti-RV effect of puerarin has not been studied, so we used network pharmacology to analyze the anti-RV effect of puerarin and further carried out experimental verification. The complex molecular correlation of targets and pathways for puerarin against $\mathrm{RV}$ was comprehensively and systematically analyzed via the construction of puerarin-RV-target and target-pathway networks.

In this study, we evaluated the anti-RV effect of puerarin, and then determined the potential targets and pathways of puerarin against RV via network pharmacology analysis. Subsequently, an in vitro Caco-2 cell model infected with the human RV G1P[8] was established to verify the potential mechanisms of puerarin against RV. We present the following article in accordance with the MDAR reporting checklist (available at https://dx.doi.org/10.21037/ atm-21-6089).

\section{Methods}

\section{Reagents and antibodies}

Puerarin (purity $\geq 98 \%$ ) (Shanghai Yuanye Biotechnology Co., Ltd. Shanghai, China) was dissolved in dimethyl sulfoxide (DMSO) and diluted in Dulbecco's-modified Eagle's medium (DMEM, Gibco, Grand Island, NY, USA). The concentration of DMSO in the culture medium was less than $0.02 \%$. The DMEM + DMSO solution was applied as the parallel solvent control. TRIzol, fetal bovine serum (FBS), and $100 \mathrm{U} / \mathrm{mL}$ penicillin-streptomycin mixture were purchased from ExCell Bio Co., Ltd. (Shanghai, China). Cell Counting Kit-8 (CCK-8) was obtained from Dojindo Laboratories (Kumamoto, Japan). The reverse transcription kits were obtained from Takara Biological Engineering Co., Ltd. (Beijing, China). The bicinchoninic acid protein assay kits and electrochemiluminescence (ECL) reagent 
were purchased from Solarbio Science \& Technology Co., Ltd. (Beijing, China). Antibodies against Toll-like receptor 4 (TLR4), myeloid differentiation primary response 88(MyD88), tumor necrosis factor receptor-associated factor 6 (TRAF6), nuclear factor kappa-B p65 (p65) and posphorylation p65 (p-p65), and secondary antibodies were obtained from Abcam (Cambridge, UK). Enzyme-linked immunosorbent assay (ELISA) kits for tumor necrosis factor (TNF)- $\alpha$, interferon- $\gamma$ (IFN- $\gamma$ ), interleukin $1 \beta$ (IL-1 $\beta$ ), and IL-6 were purchased from Boster Biological Technology Co., Ltd. (Wuhan, China).

\section{Cells and virus}

Caco-2 cells obtained from the Cell Bank of Type Culture Collection of the Chinese Academy of Sciences (Shanghai, China) were grown in DMEM containing 10\% FBS (Gibco, USA) and antibiotics $(100 \mathrm{U} / \mathrm{mL}$ penicillin and $100 \mathrm{mg} / \mathrm{mL}$ streptomycin) at $37{ }^{\circ} \mathrm{C}$ in $5 \% \mathrm{CO}_{2}$. The human RV G1P[8] Wa strain (HRV Wa) was originally obtained from the Institute of Viral Disease Control and Prevention of the Chinese Center for Disease Control and Prevention. HRV Wa pre-activated with trypsin was inoculated on Caco-2 cells at a constant temperature of $37{ }^{\circ} \mathrm{C}$ in $5 \% \mathrm{CO}_{2}$. The $50 \%$ tissue culture infective dose (TCID50) was determined by the Reed-Muench method (TCID50 $\left.=10^{-4.39} / 100 \mu \mathrm{L}\right)(18)$.

When the cytopathic effect (CPE) exceeded $90 \%$, the culture was stopped. The virus culture was frozen and thawed three times, and centrifuged at 1,000 rpm for 10 minutes. The supernatant was then taken and stored at $-80^{\circ} \mathrm{C}$ for later use.

\section{Cell viability assay}

The viability of Caco-2 cells incubated with puerarin was determined using CCK- 8 assays. Caco- 2 cells $\left(4 \times 10^{4}\right.$ cells/ well) were inoculated in 96-well plates and incubated for $24 \mathrm{~h}$ at $37{ }^{\circ} \mathrm{C}$ in $5 \% \mathrm{CO}_{2}$. Puerarin at different concentrations $(10,20,40,80,160,320,640,1,280$, and $2,560 \mu \mathrm{M})$ was then added to the wells. Three wells were set for each concentration, and the normal cell control was set simultaneously. After $24 \mathrm{~h}$ of treatment, CCK-8 (10 $\mu \mathrm{L} /$ well) was added, and the cells were incubated for an additional $2 \mathrm{~h}$. The absorbance at $450 \mathrm{~nm}$ was detected using a microplate reader(Sigma, USA). The $50 \%$ cytotoxic concentration (CC50) of puerarin was calculated using a previously described method (19).

\section{Antiviral effects of puerarin}

To evaluate the antiviral effect of puerarin against HRV Wa, non-toxic concentrations of puerarin were used to treat Caco-2 cells, and virus-inhibition experiments were performed for different times of virus infection (19). Briefly, for the pre-treatment with puerarin prior to HRV Wa infection, the cells were treated with different concentrations of puerarin for $2 \mathrm{~h}$. Next, the supernatant was replaced by medium containing 100 TCID50/mL HRV Wa. After $2 \mathrm{~h}$ of infection, the supernatant was removed, and the cells were the cultured at $37{ }^{\circ} \mathrm{C}$ in $5 \% \mathrm{CO}_{2}$ for another $24 \mathrm{~h}$. For the co-treatment with puerarin and HRV Wa (100 TCID50/mL), the virus solution was treated with puerarin of different concentrations at $4{ }^{\circ} \mathrm{C}$ for $6 \mathrm{~h}$, and the mixture was then used to inoculate Caco-2 cells. After incubation at $37^{\circ} \mathrm{C}$ for $2 \mathrm{~h}$, the mixture was removed, and the cells were cultured with maintenance medium for another $24 \mathrm{~h}$.

For the post-treatment with puerarin after $100 \mathrm{TCID} 50 / \mathrm{ml}$ HRV Wa infection, Caco-2 cells were inoculated with virus solution. After adsorption at $37{ }^{\circ} \mathrm{C}$ for $2 \mathrm{~h}$, the supernatant was discarded, and puerarin at different concentrations was subsequently added to the culture for another $24 \mathrm{~h}$. Finally, ten microliters of CCK-8 were added into each well for $2 \mathrm{~h}$, and the absorbance at $450 \mathrm{~nm}$ was detected using a microplate reader. The drug selectivity index (SI) was calculated based on the ratio of the CC50 to $50 \%$ effective concentration (EC50) of the test drug. All experiments were performed in triplicate.

\section{Network pharmacology analysis}

Structural information on puerarin was obtained from the NCBI PubChem database (https://pubchem.ncbi. nlm.nih.gov/) (20), a public database of the biological properties and chemical structures of small molecules. The potential targets of puerarin were collected from the following target prediction databases: the traditional Chinese medicine systems pharmacology (TCMSP) Database (http://lsp.nwsuaf.edu.cn/tcmsp.php), the Swiss Target Prediction Database (http://www.swisstargetprediction. ch/), the STITCH Database (http://stitch.embl.de/), and the PharmMapper Database (https://lilab.ecust.edu.cn/ pharmmapper/index.php). The targets of RV were obtained from the following three databases: the Online Mendelian Inheritance in Man (OMIM) Database (http://omim.org/) (21), the DisGeNET database (https://www.disgenet.org/), 
Table 1 Primer sequence for RT-qPCR

\begin{tabular}{lll}
\hline Target & Forward $\left(5^{\prime}\right.$ to 3$)$ & Reverse $\left(5^{\prime}\right.$ to 3$)$ \\
\hline TLR4 & AGGTTTCCATAAAAGCCGAAAG & CAATGAAGATGATACCAGCACG \\
MyD88 & CGCCGCCTGTCTCTGTTCTTG & GGTCCGCTTGTGTCTCCAGTTG \\
TRAF6 & GCAGAGAAGGCGGAAGCAGTG & TGGTAGAGGACGGACACAGACAC \\
$\beta$-actin & CCCATCTATGAGGGTTACGC & TTTAATGTCACGCACGATTC \\
\hline
\end{tabular}

RT-qPCR, real-time reverse transcription PCR; TLR4, Toll-like receptor 4.

and the GeneCards Human Genes database (https://www. genecards.org/). The keywords searched were "rotavirus infection" and "rotavirus". The UniProt database (https:// www.uniprot.org/) (22) was adopted to convert the protein names of target genes into their corresponding gene symbols. The targets of RV and puerarin were mapped using Venny 2.1 (http://bioinfogp.cnb.csic.es/tools/venny/ index.html) to acquire their common targets.

The protein-protein interaction (PPI) network is a complex network expressing the interactions among target genes. The common targets of puerarin and RV were imported into the STRING database (https://string-db. org/) (23) to generate a file of the interaction relationships among targets, which was then imported into the Cytoscape database (24) for visual processing. The functional annotation of the target genes was analyzed using DAVID 6.8 (https:// david.ncifcrf.gov/home.jsp) (25), an annotated database for understanding the biological significance of a large number of genes. In addition, the species and background were set as "Homo sapiens" in KEGG pathway analysis.

\section{Real-time quantitative polymerase chain reaction (RT-qPCR) analysis}

The total RNA of Caco-2 cells was extracted with TRIzol (Invitrogen, Carlsbad, CA, USA). The concentration of the extracted RNA was determined using an ultramicrospectrophotometer (ExCell MINIDROP), and the quality of the RNA was determined by nucleic acid electrophoresis. The RNA was subsequently reverse transcribed to cDNA using a reverse transcription kit (Takara, China). Real-time PCR was performed using the SYBR Green qPCR Master Mix (2×) (ExCell, Shanghai, China) and a Light Cycler 480 II (Roche, Indianapolis, USA). Briefly, the reaction system was prepared as follows: $2 \mu \mathrm{L}$ of cDNA template, the forward primer and reverse primer at $1 \mu \mathrm{L}$ each, $12.5 \mu \mathrm{L}$ of SYBR Green qPCR Master Mix (2×), and
$8.5 \mu \mathrm{L}$ of $\mathrm{ddH}_{2} \mathrm{O}$. The $\mathrm{RT}-\mathrm{qPCR}$ procedure was as follows: $10 \mathrm{~min}$ at $95^{\circ} \mathrm{C}$ (pre-denaturation), 40 cycles at $95^{\circ} \mathrm{C}$ for $20 \mathrm{~s}, 58^{\circ} \mathrm{C}$ for $30 \mathrm{~s}$, and $72{ }^{\circ} \mathrm{C}$ for $20 \mathrm{~s} \mathrm{(circular} \mathrm{reaction).}$ Table 1 displays the sequences of primers. The mRNA levels were calculated using the $2^{-\Delta \Delta \mathrm{CT}}$ method and normalized to $\beta$-actin.

\section{Western blot analysis}

The expression of key proteins of the TLR4/NF- $\kappa \mathrm{B}$ signaling pathway was quantified by western blot. Total protein was extracted from Caco-2 cells, and the protein concentration was measured using the BCA method. The protein samples were separated by $12 \%$ SDS-PAGE and then transferred to a $0.2 \mu \mathrm{m}$ PVDF membrane (Millipore, USA) (19). The membrane was washed three times with TBST for 1 min each time, blocked with 5\% skim milk powder at $25^{\circ} \mathrm{C}$ for $3 \mathrm{~h}$, and incubated with the following primary antibodies at $4{ }^{\circ} \mathrm{C}$ overnight: anti-TLR4 $(2 \mu \mathrm{g} / \mathrm{mL})$, anti-MyD88 (1:750), anti-TRAF6 $(1: 5,000)$, anti-p65 $(1: 1,000)$, anti-phospho-p65 (1:1,000), and $\beta$-actin $(1: 5,000)$. The membranes were washed five times with TBST for 10 min each time and incubated with secondary antibody at $25^{\circ} \mathrm{C}$ for $1 \mathrm{~h}$. Subsequently, after washing the membrane five times with TBST, ECL reagent was used to detect the protein signals, and the Image J software (NIH, USA) was used to analyze the optical density of the bands.

\section{ELISA}

Caco-2 cells were inoculated with HRV Wa. After adsorption at $37^{\circ} \mathrm{C}$ for $2 \mathrm{~h}$, the supernatant of the RV Wa strain was discarded and the cells were washed with PBS. Normal cells and RV-infected cells were set as controls, and $0.1 \%$ DMSO was added. Puerarin at different concentrations was added to the other groups, with three duplicate wells in each group. After the cells were cultured 

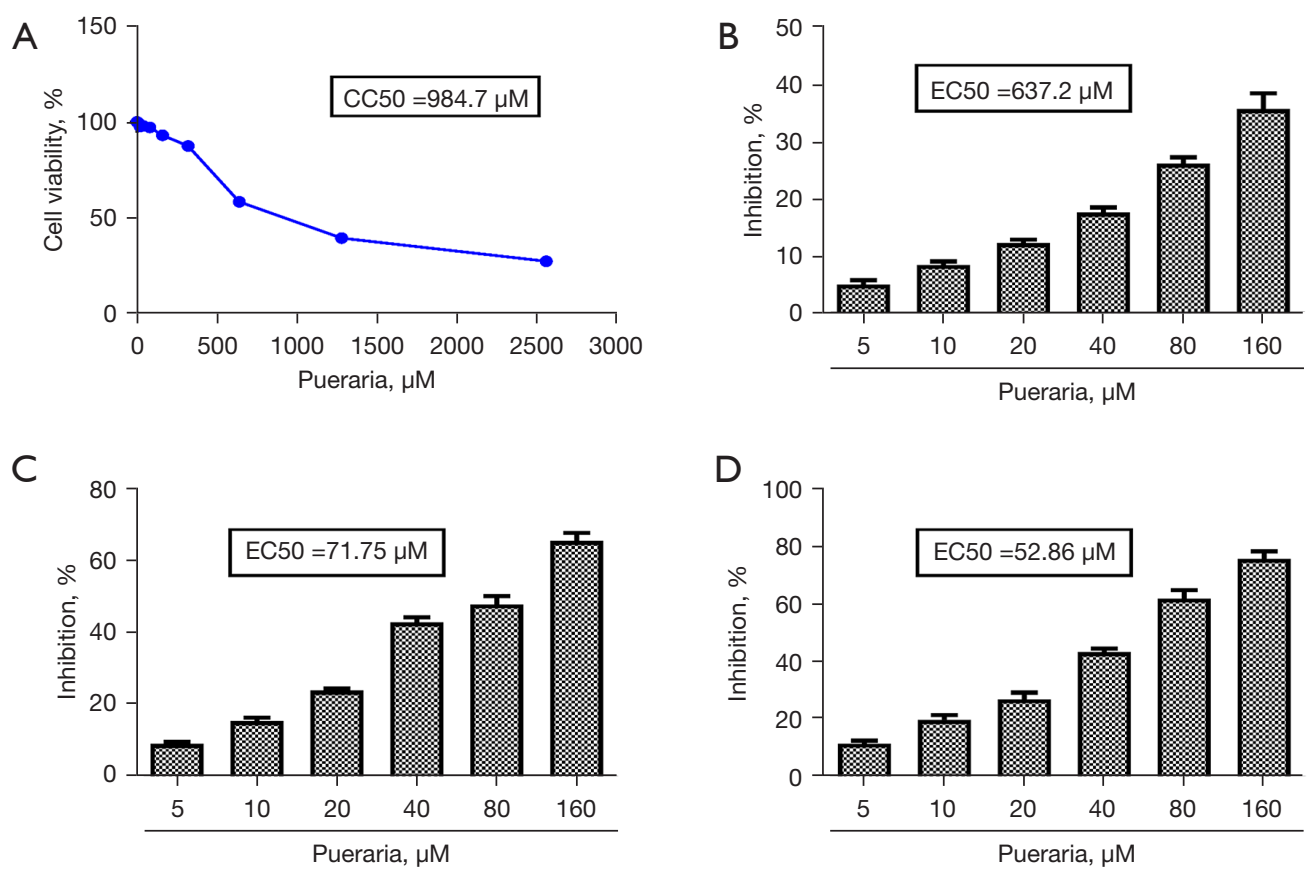

Figure 1 The inhibition rate of puerarin on HRV Wa inoculated at different stages in vitro. (A) The viability of Caco-2 cells incubated with puerarin was determined using CCK-8 assays. The inhibition of puerarin on HRV Wa in Caco-2 cells at pre-treatment (B), co-treatment (C), and post-treatment (D). All data were presented as the mean \pm SD of three individual experiments. HRV Wa, human RV G1P[8] Wa strain; CCK-8, Cell Counting Kit-8.

in $5 \% \mathrm{CO}_{2}$ at $37{ }^{\circ} \mathrm{C}$ for $24 \mathrm{~h}$, the supernatant of cells was collected. The levels of TNF- $\alpha$, IL- $1 \beta$, IL- 6 , and IFN- $\gamma$ in each group were assessed using an ELISA kit, according to the manufacturer's instructions.

\section{Statistical analysis}

All data were shown as mean \pm standard deviation (SD). one-way analysis of variance (ANOVA) was used to analyze the experimental results via the SPSS statistics v22.0 software (IBM, USA), followed by a least-significantdifference (LSD) test for multiple comparisons. $\mathrm{P}<0.05$ was considered statistically significant.

\section{Results}

\section{Inbibitory effects of puerarin on $H R V W a$ in vitro}

The CC50 of puerarin toward Caco-2 cells was $984.7 \mu M$ (Figure $1 A$ ). As the concentration of puerarin increased, the cell viability of Caco-2 cells gradually decreased. When the concentration of puerarin exceeded $160 \mu \mathrm{M}$, the cell survival rate was less than $90 \%$, so the maximum concentration we chose for subsequent experiments was $160 \mu \mathrm{M}$ (Figure 1A). When the Caco-2 cells were pre-treated with puerarin for $2 \mathrm{~h}$, the EC50 of puerarin was $637.2 \mu \mathrm{M}$ (Figure $1 B$ ) and the SI was 1.55. In the co-treatment experiment, the EC50 of puerarin was $71.75 \mu \mathrm{M}$ (Figure $1 C$ ) and the SI was 13.72. Moreover, the EC50 of puerarin was $52.86 \mu \mathrm{M}$ (Figure 1D) and the SI was 18.63 in the post-treatment experiment. These results showed that puerarin exerted an anti-RV effect mainly by inhibiting viral replication and proliferation. Furthermore, the antiviral effect of puerarin increased with the increasing concentration. As the antiviral effect of puerarin in the posttreatment experiment was superior to that in the other two experiments, puerarin treatment after HRV Wa infection was used in the following experiments.

Two hours after the RV infection, the effect of puerarin on the pathological changes of virus-infected Caco-2 cells was observed under the microscope (Figure 2). Caco-2 cells in the normal control (NC) group were oval, uniform in shape, and tightly connected, with clear cell edges and fast growth. Caco-2 cells in the RV group showed an uneven 


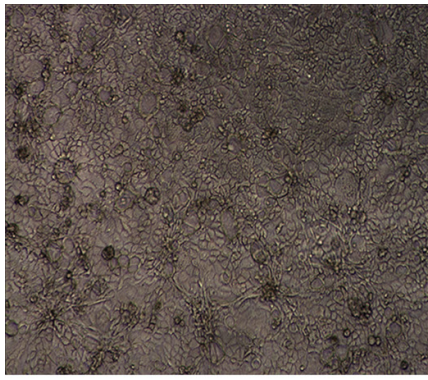

NC

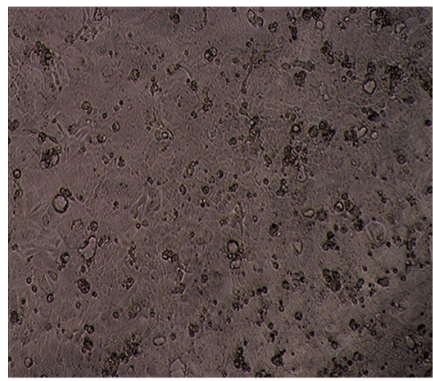

$\mathrm{RV}+$ puerarin $20 \mu \mathrm{M}$

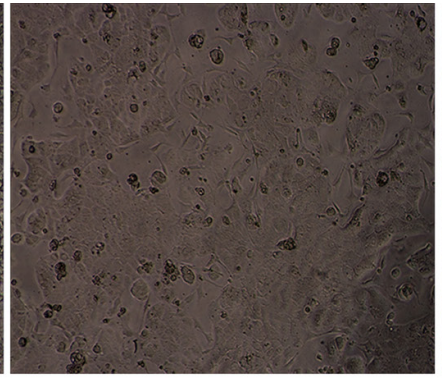

RV

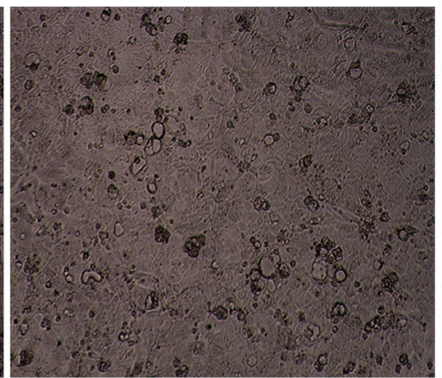

$\mathrm{RV}+$ puerarin40 $\mu \mathrm{M}$

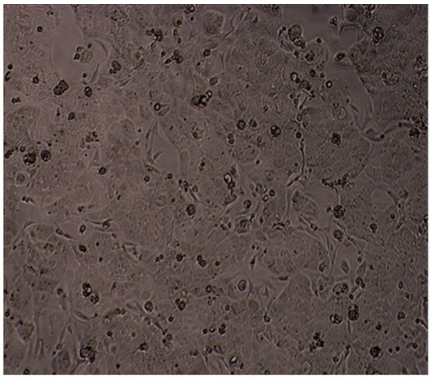

$\mathrm{RV}+$ puerarin $5 \mu \mathrm{M}$

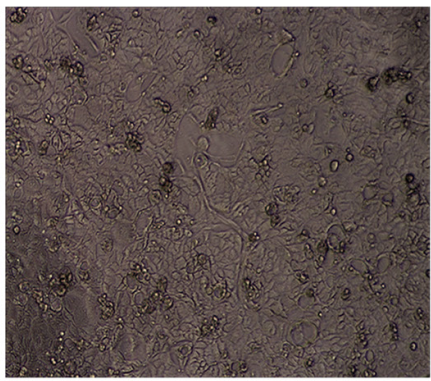

$\mathrm{RV}+$ puerarin $80 \mu \mathrm{M}$

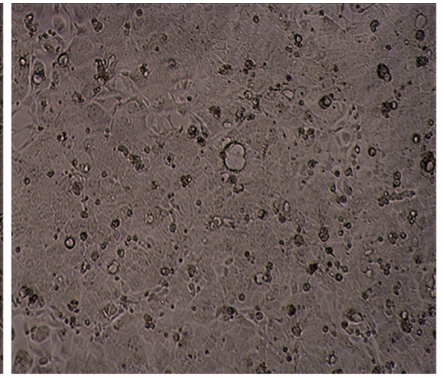

$\mathrm{RV}+$ puerarin $10 \mu \mathrm{M}$

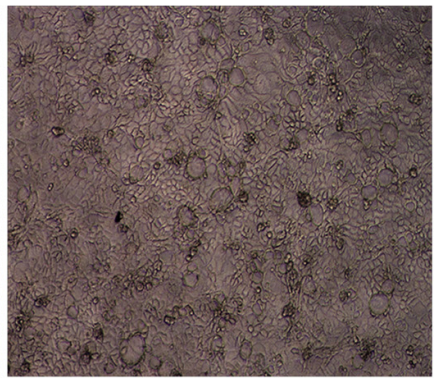

$\mathrm{RV}+$ puerarin $160 \mu \mathrm{M}$

Figure 2 The effect of puerarin $(5,10,20,40,80$, and $160 \mu \mathrm{M})$ on the pathological changes of HRV Wa-infected Caco-2 cells in the posttreatment experiment (40×). HRV Wa, human RV G1P[8] Wa strain; NC, normal control; RV, rotavirus.

morphology with vacuoles, enlarged intercellular spaces, blurred edges, and slow growth. Some cells were not firmly attached to the wall, and the number of dead cells and amount of cell debris increased. The pathological changes caused by HRV Wa were reduced when puerarin was applied to the Caco-2 cells. As the concentration of puerarin increased, the number of dead cells and cell vacuoles decreased, and the edges of the cells became clearer and more tightly connected.

\section{Network pharmacology results}

Puerarin is a flavonoid extracted from the root of Pueraria lobata (Willd) Ohwi, and its two-dimensional structure is shown in Figure $3 \mathrm{~A}$. A total of 436 corresponding target genes were identified via the Swiss Target Prediction, STITCH, and the PharmMapper databases, which were used to construct a PPI network consisting of 437 nodes (Figure $3 B$ ). After merging and removing duplicate projects, a total of $497 \mathrm{RV}$-related targets were acquired from the OMIM, GeneCards, and DisGeNET databases (Figure 4). After target mapping, 52 overlapped targets were obtained as the related targets of puerarin against RV (Figure $5 A$ and Table 2). These 52 targets were analyzed by STRING and visualized with Cytoscape 3.7.2. We removed the target NMNAT1, as it had no interaction with other targets, and finally obtained a PPI network with 51 targets and 384 edges (Figure 5B).

The color and size of the node are proportional to the degree value of the target. The hub targets, which might play a crucial role in RV infection, were TLR4, TNF, caspase 3 (CASP3), endothelial growth factor receptor (EGFR), and IL-2. Among these targets, TLR4 is involved in biological processes such as inflammation, and the immune response. KEGG pathway enrichment analysis of the 51 candidate targets was performed to elucidate the specific mechanism of the effect of puerarin against RV. Subsequently, a total of 85 pathways were acquired, 52 of which were statistically significant $(\mathrm{P}<0.01)$. As shown in Figure 6, the inhibition of RV by puerarin may be mainly related to the TLR, TNF, and Phosphatidylinositol 3 kinase/protein kinase B (PI3K/ Akt) signaling pathways.

In order to further illustrate the relationship between the crucial KEGG pathways and the corresponding targets, we constructed a target-pathway network, according to the $P$ value. As shown in Figure 7, the TLR signaling pathway was mainly related to targets such as TLR4, TNF, inhibitor 
A<smiles>[N][C@]1(C2C(O)=CCC3C(=O)C(c4ccc(O)cc4)COC32)OC(CO)C(O)C(O)C1O</smiles>

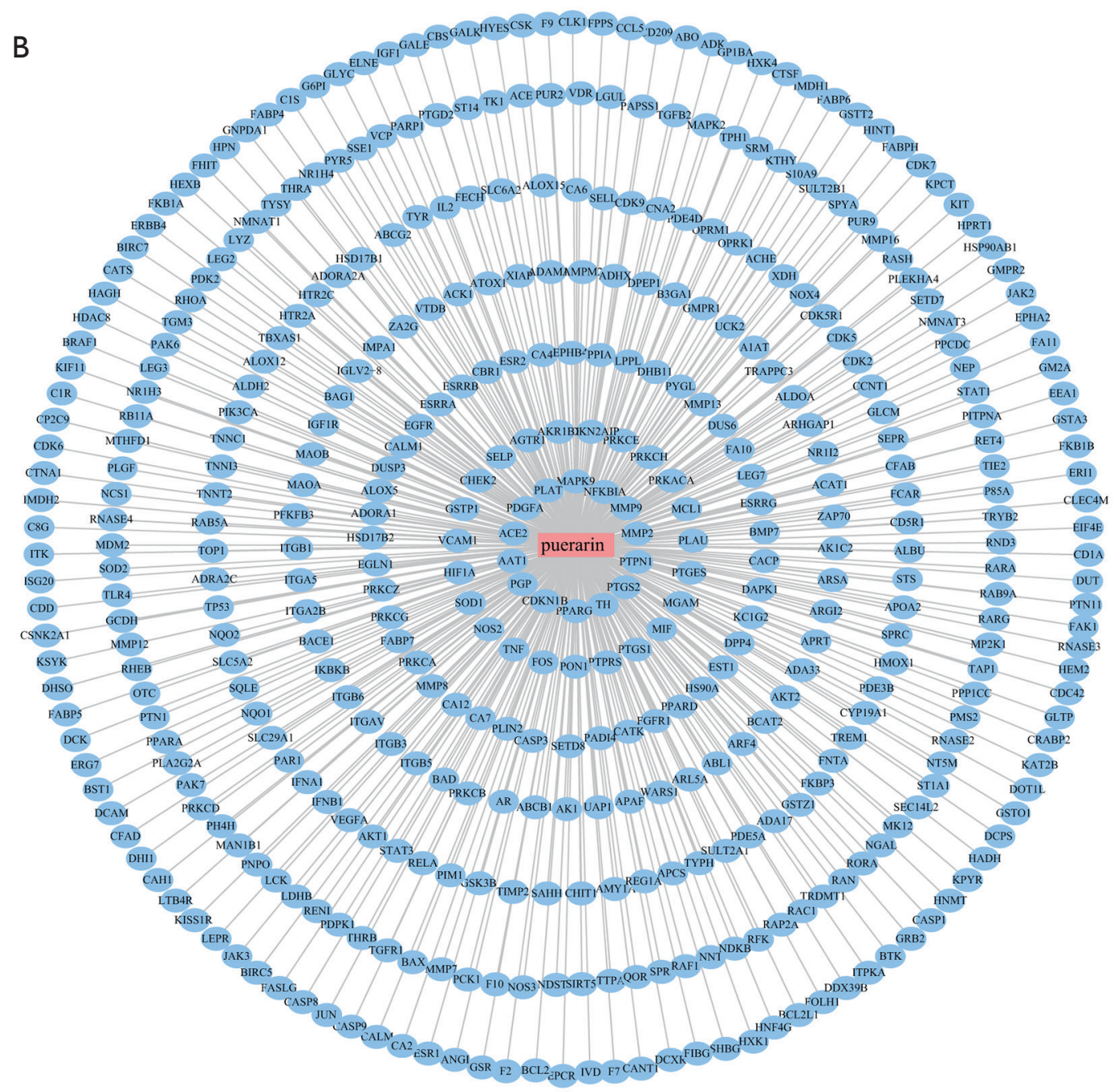

Figure 3 The PPI network of the puerarin. (A) The 2D structure of puerarin. (B) 436 candidate targets of puerarin were identified to establish the PPI network. The blue nodes represent the target protein of puerarin. PPI, protein-protein interaction. 


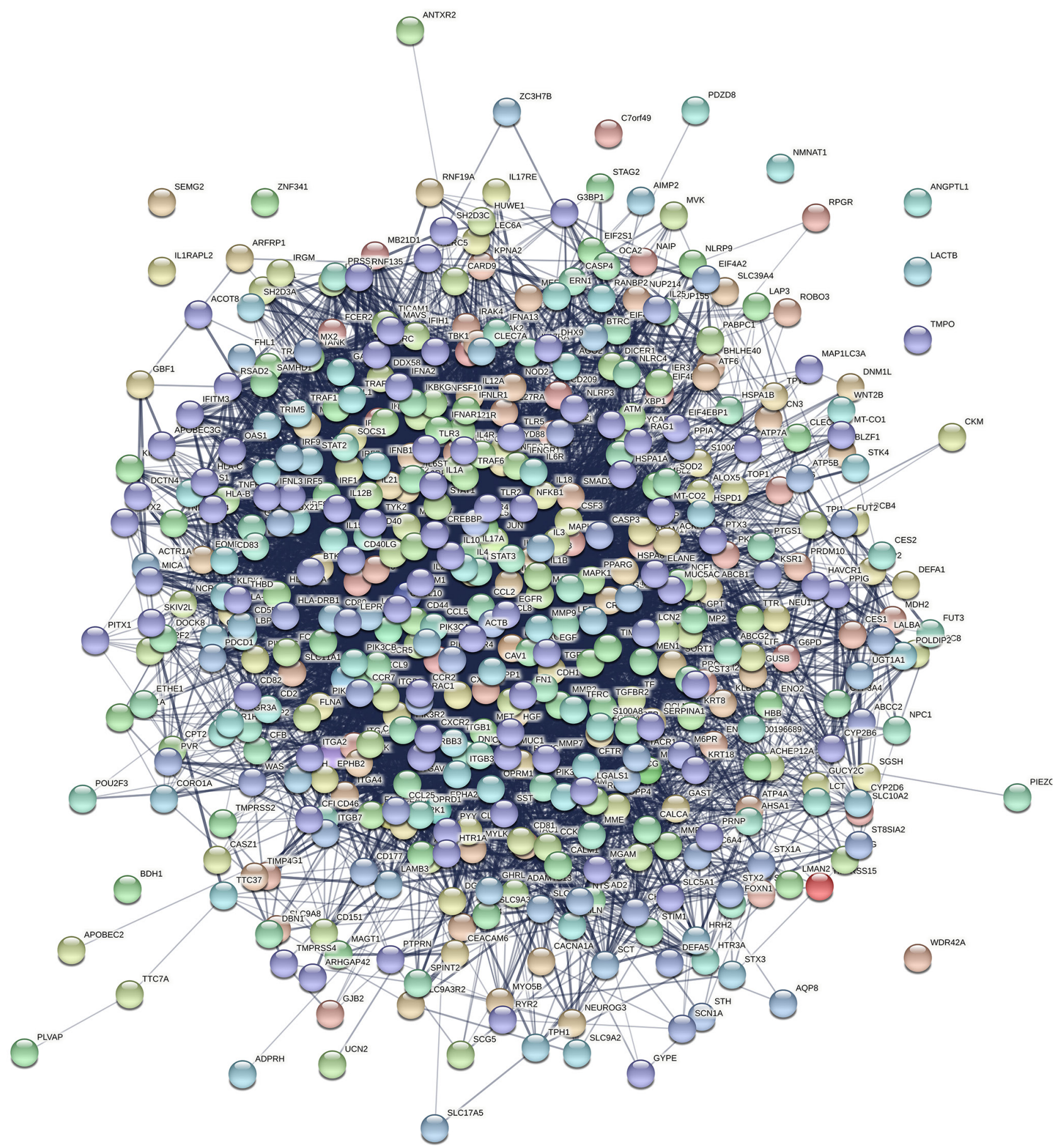

Figure 4 The corresponding targets of RV. RV, rotavirus.

of nuclear factor kappa B kinase subunit B (IKBKB), IFNB1, and IFNA1. Therefore, in the following in vitro experiments, we focused on the TLR4 signaling pathway to study the anti-RV mechanism of puerarin.

\section{Effect of puerarin on the TLR4/NF- $\kappa$ B signaling} pathway

In previous experiments, within the range of puerarin concentration $\leq 160 \mu \mathrm{M}$, the anti-RV effect of puerarin 


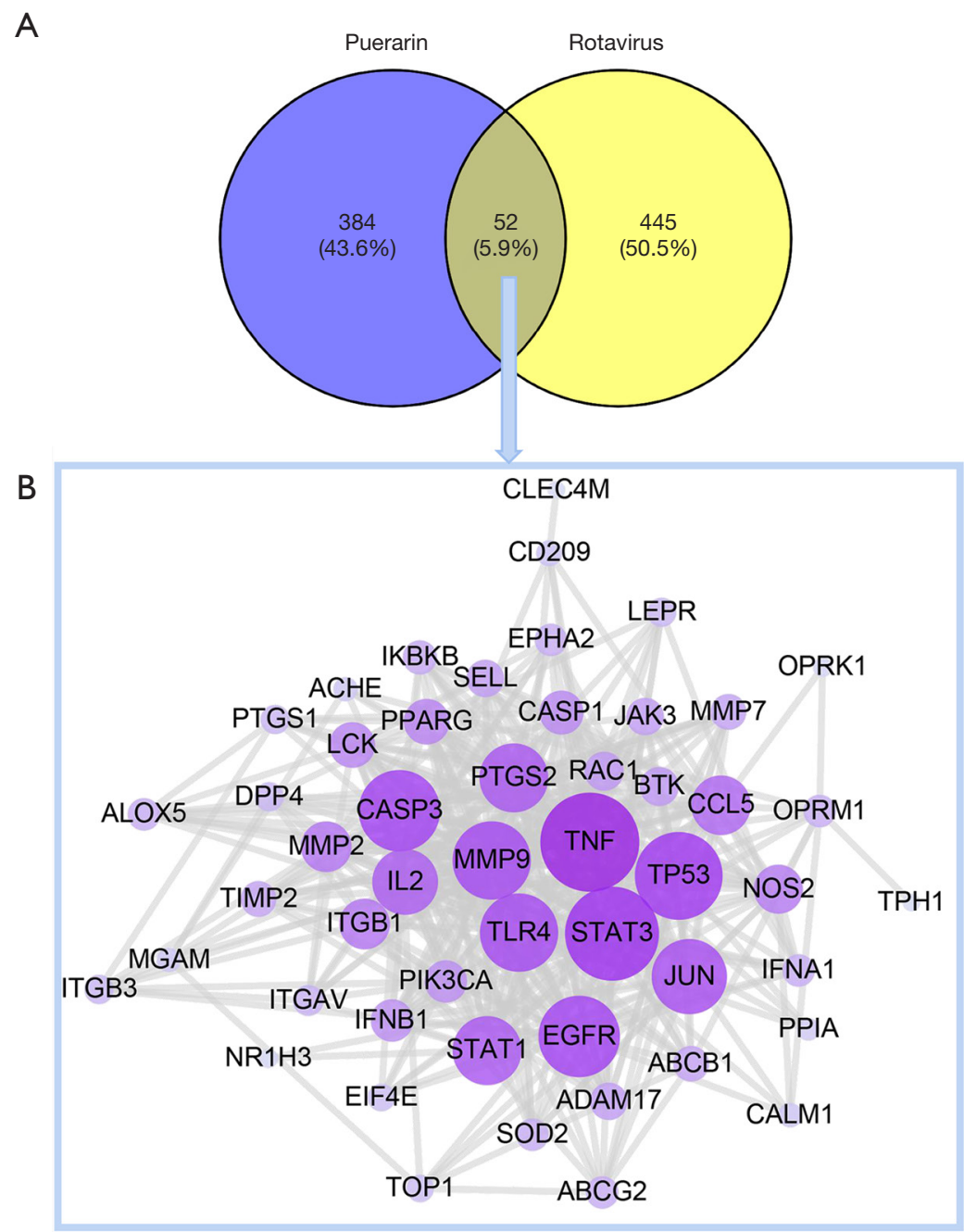

Figure 5 The collective targets of puerarin and RV were identified. (A) The Venn diagram of the overlapped and specific targets among puerarin and RV. (B) The PPI network of puerarin-RV. RV, rotavirus; PPI, protein-protein interaction.

increased with the increase of concentration. Therefore, the concentrations of 40,80 , and $160 \mu \mathrm{M}$ were used for the subsequent experiments. In order to further evaluate the effects of puerarin on the TLR4/NF- $\mathrm{BB}$ signaling pathway in RV-infected Caco-2 cells, the expression of key genes and proteins was measured by western blot and RTqPCR. The results showed that the protein expression of TLR4, MyD88, TRAF6, and p-p65 significantly increased in Caco-2 cells infected with HRV Wa. However, upon post-treatment with puerarin at different concentrations for $24 \mathrm{~h}$, the expression of these proteins decreased $(\mathrm{P}<0.05)$. Moreover, the decrease was the most notable for puerarin at $160 \mu \mathrm{M}$ (Figure 8).

Similar results at the mRNA levels were observed by
RT-qPCR. As shown in Figure 9, the mRNA expression of TLR4, MyD88, and TRAF6 was significantly upregulated in Caco-2 cells infected with HRV Wa $(\mathrm{P}<0.05)$. After treatment with puerarin for $24 \mathrm{~h}$, the mRNA expression of TLR4, MyD88, and TRAF6, in HRV Wa-infected Caco-2 cells decreased considerably $(\mathrm{P}<0.05)$.

\section{Puerarin modulated the inflammation of HRV Wa-infected cells}

It is well known that RV infection could cause a strong inflammatory response. In order to further assess the effect of puerarin on the inflammatory response induced by $\mathrm{RV}$ infection, we detected the levels of IL-6, IL-1 $\beta$, TNF- $\alpha$, and IFN- $\gamma$ by ELISA (Figure 10). The levels of IL-6, IL- 
Table 2 Targets of puerarin in the treatment of RV

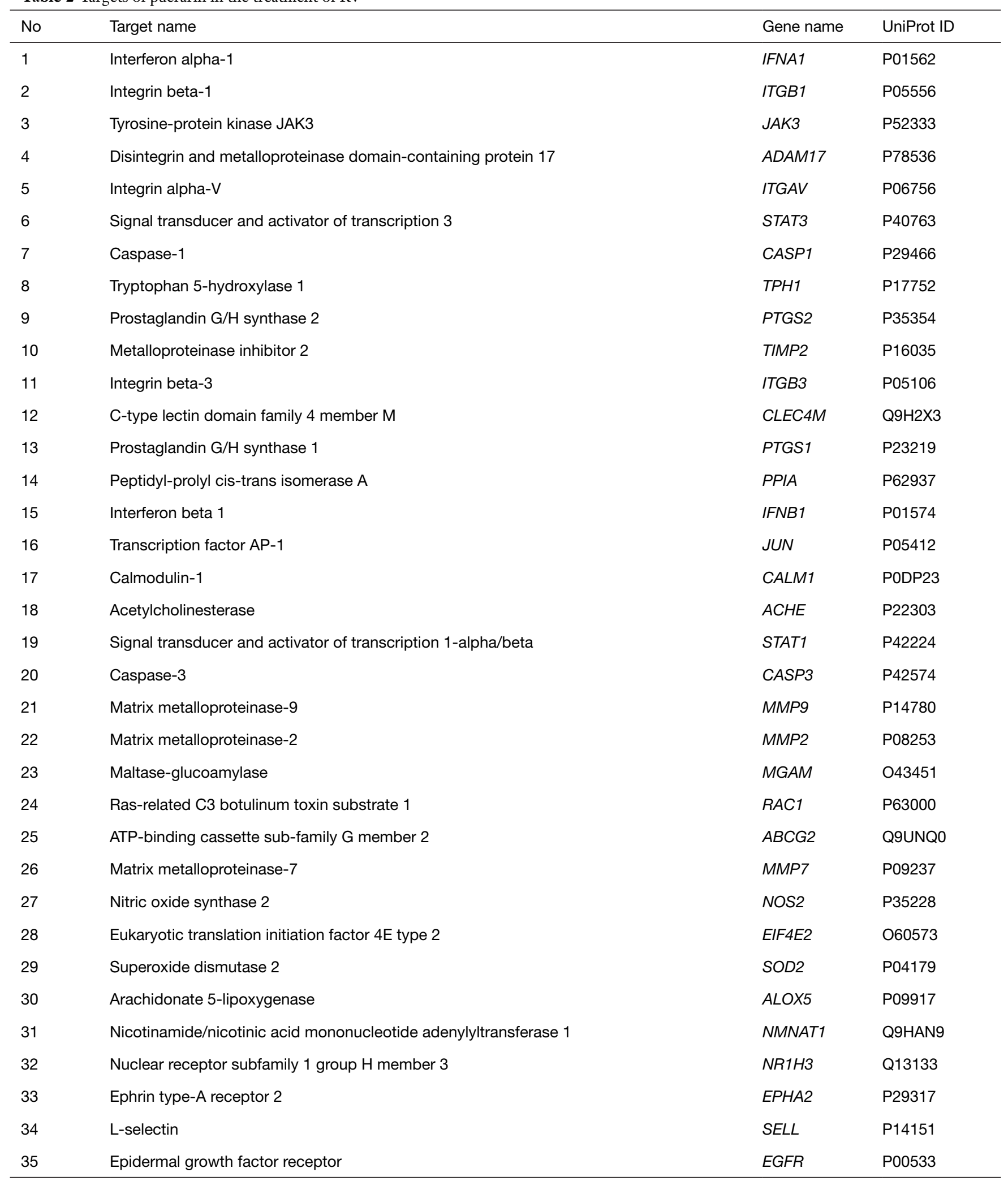

Table 2 (continued) 
Table 2 (continued)

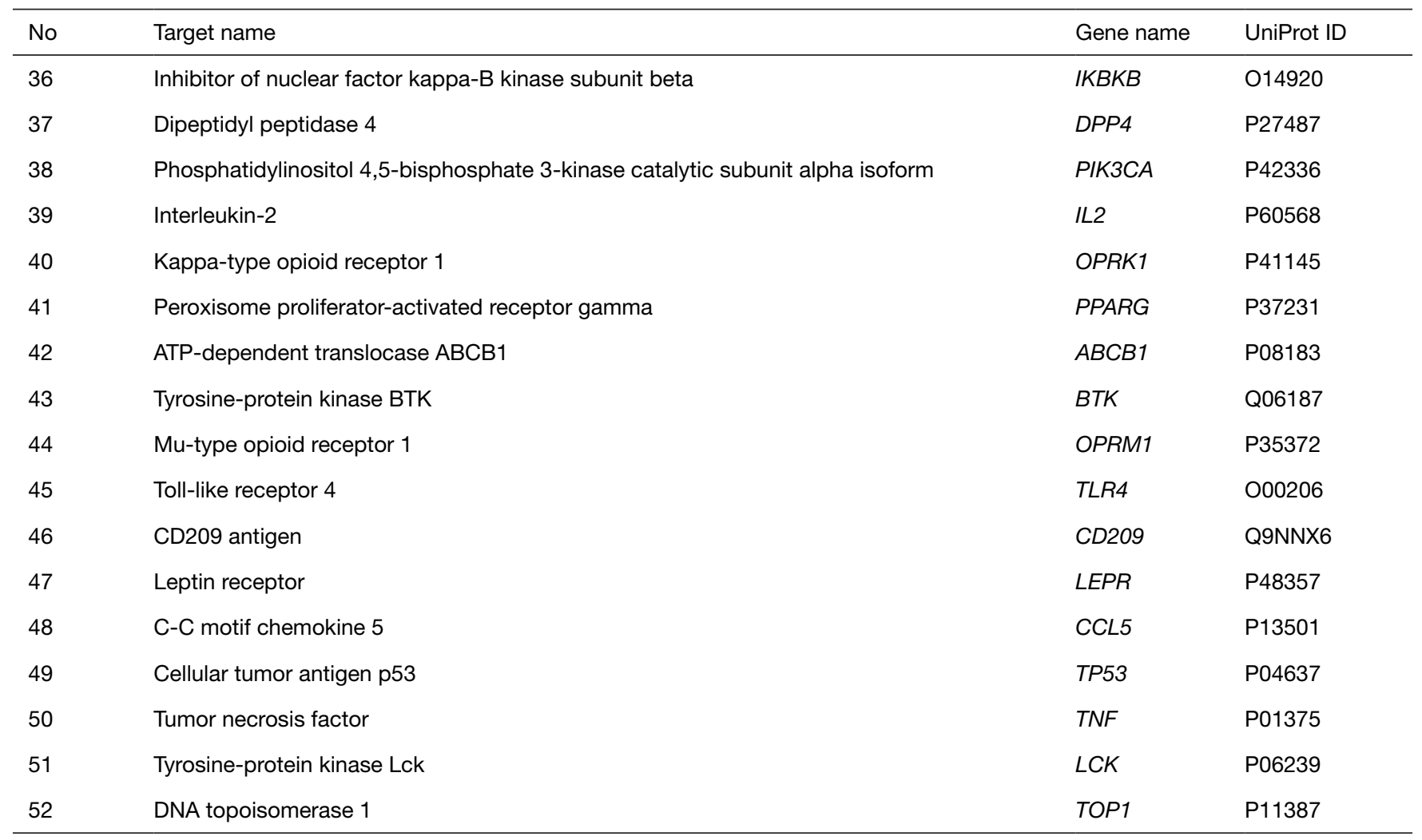

$\mathrm{RV}$, rotavirus.

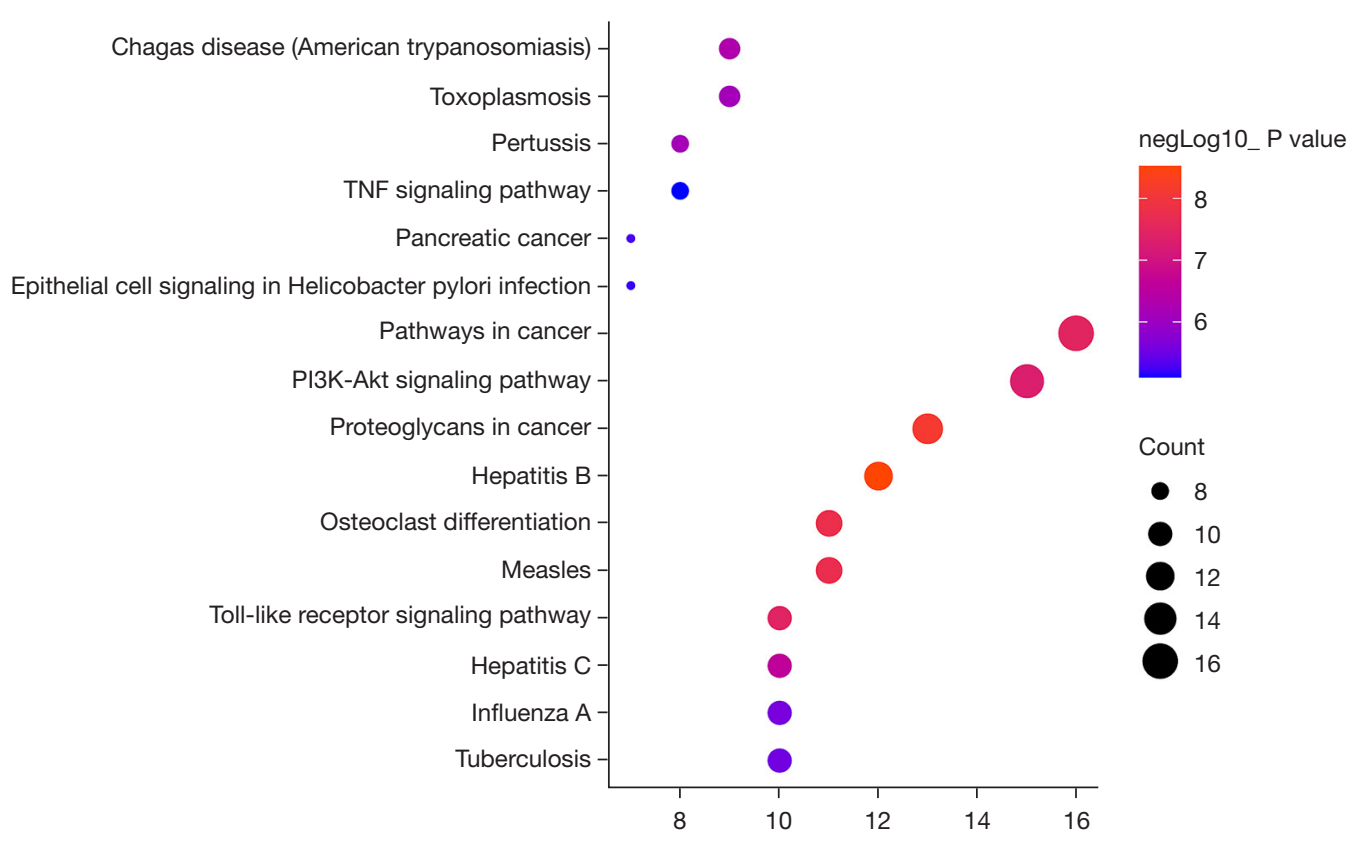

Figure 6 KEGG pathway analysis of the common targets between puerarin and RV. KEGG, Kyoto Encyclopedia of Genes and Genomes; RV, rotavirus. 


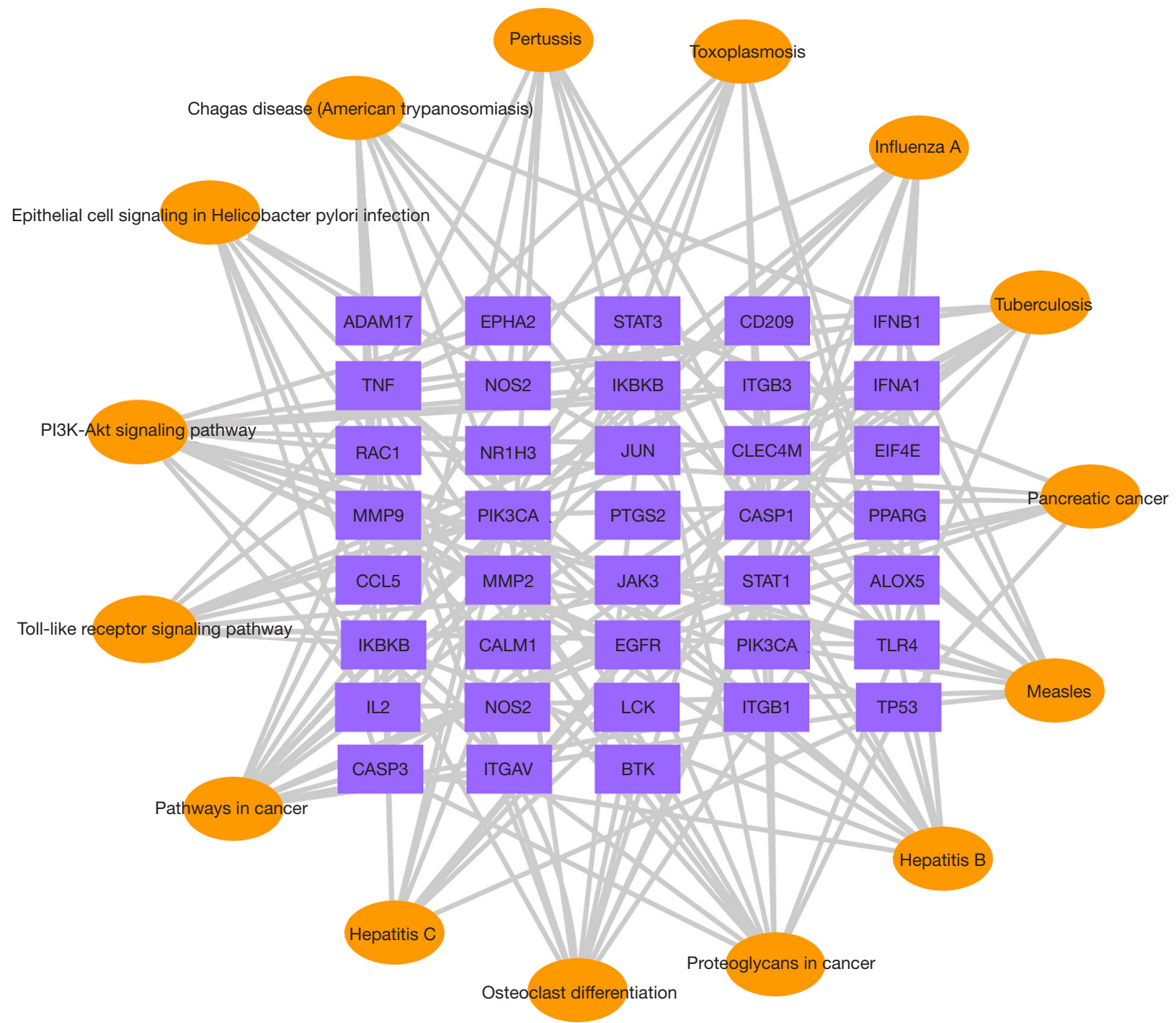

Figure 7 Targets-pathways network. The top 15 with lower $\mathrm{P}$ value are shown. The target genes of puerarin-RV are shown as a purple node, and the pathways are marked with yellow nodes. RV, rotavirus.

$1 \beta$, TNF- $\alpha$, and IFN- $\gamma$ in the RV Wa-infected cells were significantly higher than those in the $\mathrm{NC}$ group $(\mathrm{P}<0.05)$. The levels of IL-6, IL-1 $\beta$, and TNF- $\alpha$ sharply decreased after puerarin treatment, while the level of IFN- $\gamma$ increased further $(\mathrm{P}<0.05)$.

\section{Discussion}

HRV Wa is a common standard strain in RV research $(26,27)$, with strong virulence and good stability (28). According to the antigenicity of the structural proteins, VP4 and VP7 of RV, RV has been genotyped as the G and P genotypes, respectively (29). At least $37 \mathrm{G}$ and $50 \mathrm{P}$ genotypes of human and animal RVs have been distinguished (30). The most common combination of $\mathrm{G}$ and $\mathrm{P}$ genotypes of human RVs is G1P[8], G2P[4], G3P[8], G4P[8], and G9P[8], among which G1P[8] is the most prevalent worldwide (31). Caco2 cells are similar to human intestinal epithelial cells in both structure and function, and are commonly used in in vitro experiments of RV infection (32). Therefore, we studied the anti-RV effect of puerarin on Caco-2 cells infected with the HRV G1P[8] Wa strain in vitro. First, we investigated CC50 to study the toxicity of puerarin on Caco-2 cells, and the result was $984.7 \mu \mathrm{M}$, indicating that puerarin had 
A
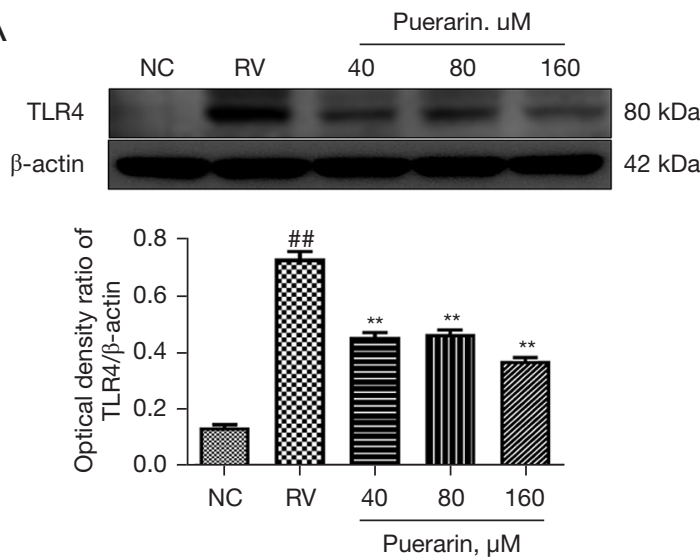

C
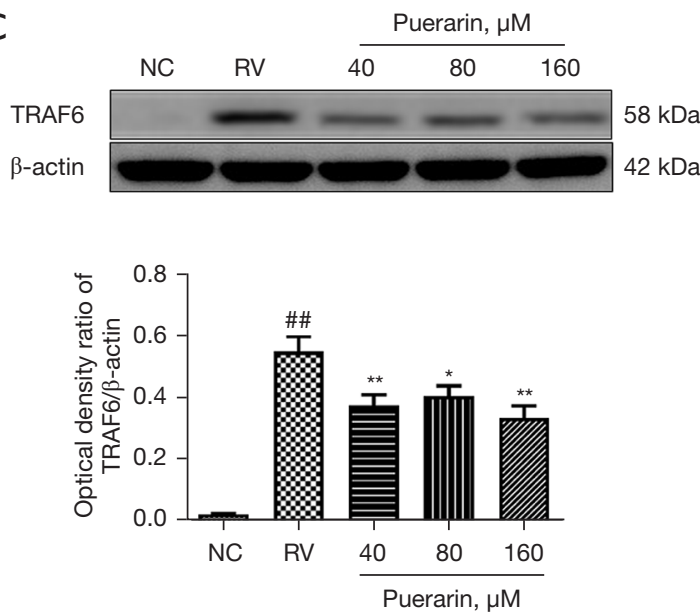
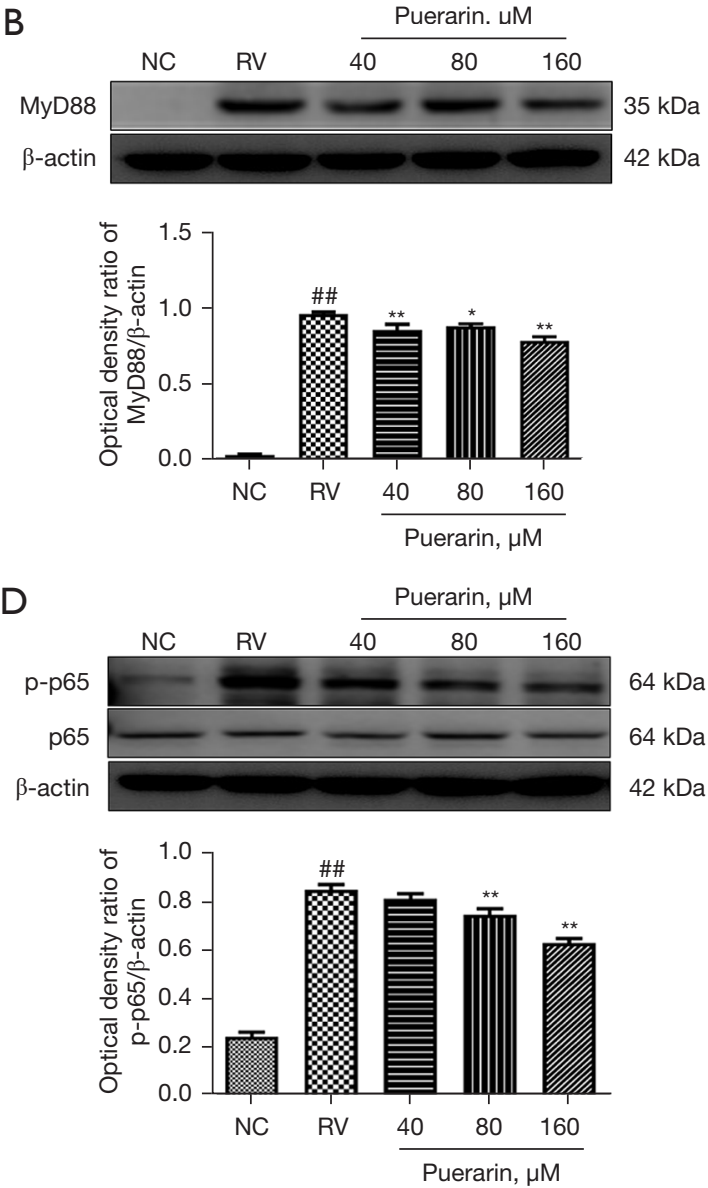

Figure 8 Puerarin decreased the expression of key proteins in the TLR4/NF-KB signaling pathway in HRV Wa-infected Caco-2 cells. The protein expression of TLR4, MyD88, TRAF6, p65, and p-p65 in Caco-2 cells was measured by western blot, and the bands were quantitatively analyzed (A-D). Significant differences between groups were indicated as ${ }^{\# \#,} \mathrm{P}<0.01 v s$. NC group; ${ }^{*}, \mathrm{P}<0.05,{ }^{* *}, \mathrm{P}<0.01 v s . \mathrm{RV}$ group, $\mathrm{n}=3$. TLR4, Toll-like receptor 4; NF-kB, nuclear factor kappa-B; HRV Wa, human RV G1P[8] Wa strain; NC, normal control; RV, rotavirus.

A

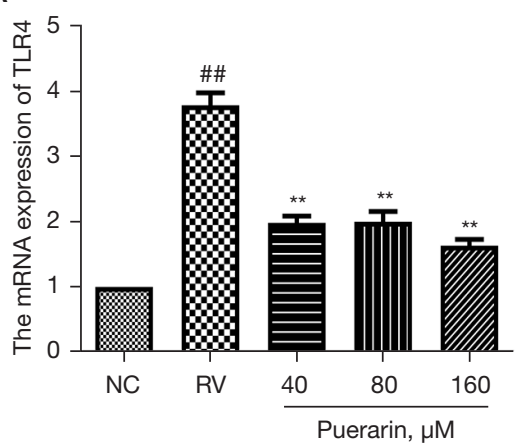

B

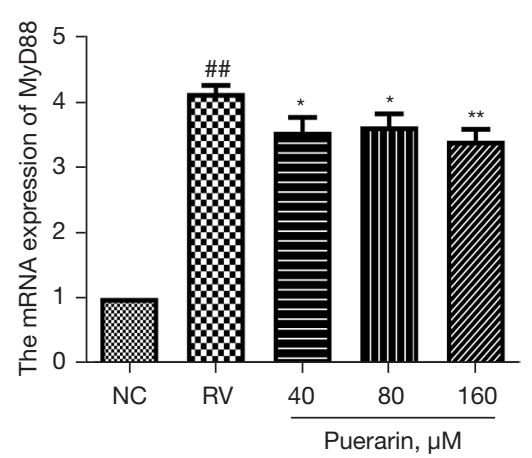

C

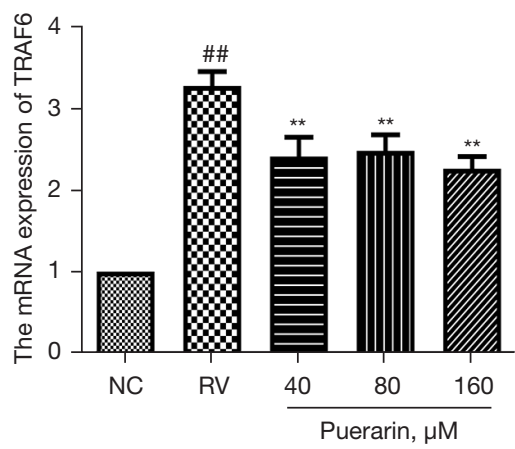

Figure 9 Puerarin decreased the mRNA expression of the TLR4, MyD88, and TRAF6, in HRV Wa-infected Caco-2 cells. The mRNA expression of the TLR4, MyD88, and TRAF6 in Caco-2 cells was detected by RT-qPCR analysis (A-C). Significant differences between groups were indicated as "\#, $\mathrm{P}<0.01$ vs. NC group; ${ }^{*}, \mathrm{P}<0.05 ;$ **, $\mathrm{P}<0.01$ vs. RV group, $\mathrm{n}=3$. TLR4, Toll-like receptor 4; HRV Wa, human RV G1P[8] Wa strain; RT-qPCR, real-time reverse transcription PCR; NC, normal control; RV, rotavirus. 

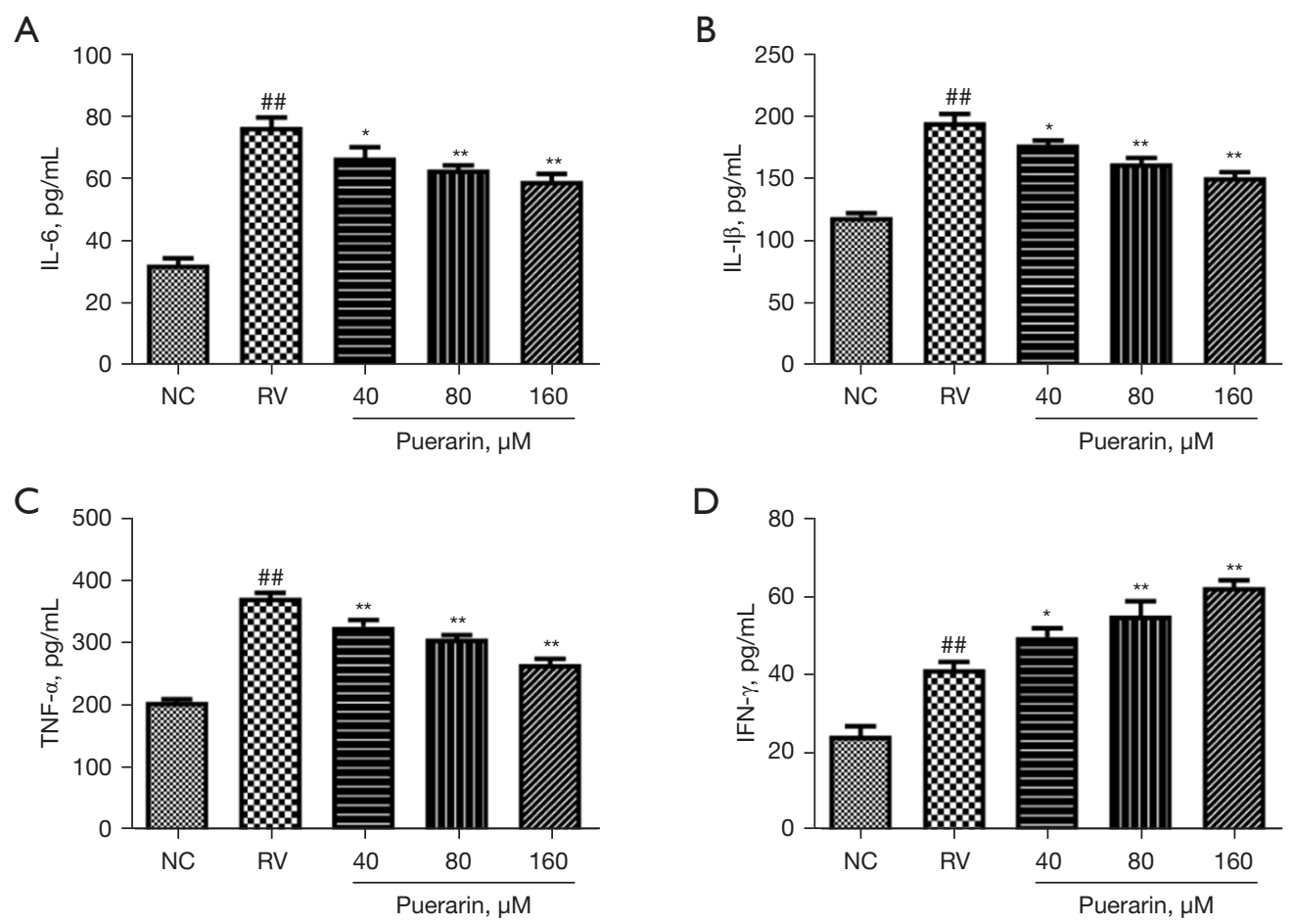

Figure 10 Puerarin modulated the inflammation of HRV Wa-infected cells. The levels of the IL-6, IL- $1 \beta$, TNF- $\alpha$, and IFN- $\gamma$ in virusinfected cells were detected by ELISA (A-D). Significant differences between groups were indicated as ${ }^{\#}, \mathrm{P}<0.01$ vs. NC group; * $\mathrm{P}<0.05$; **, $\mathrm{P}<0.01$ vs. RV group, $\mathrm{n}=3$. HRV Wa, human RV G1P[8] Wa strain; IL-1 $\beta$, interleukin $1 \beta$; TNF- $\alpha$, tumor necrosis factor- $\alpha$; IFN- $\gamma$, interferon- $\gamma$; ELISA, enzyme-linked immunosorbent assay; NC, normal control; RV, rotavirus.

low cytotoxicity. Next, the influence of puerarin (within the safe concentration range) on HRV Wa was measured before, during, and after RV infection in vitro. The results showed that puerarin could significantly inhibit HRV Wa at different stages of viral infection and reduce the cytopathic changes. Moreover, as the concentration of puerarin increased, the inhibitory effect on RV was enhanced. It is worth noting that the antiviral effect of post-treatment with puerarin was better than that of pre- and co-treatment, so post-treatment with puerarin was used in the subsequent experiments.

Compared with the previous research methods, network pharmacology confirms to the characteristics of the "overall concept" of traditional Chinese medicine, and provides new perspectives for the discovery of bioactive substances, mechanism research, quality control and many other fields. Considering the multi-component, multi-path, and multitarget features of Chinese herbal medicine, the network pharmacological method was used to further uncover the potential mechanisms of puerarin against RV. A total of 436 corresponding target genes of puerarin and $497 \mathrm{RV}$-related targets were identified, and finally 52 potential targets for the treatment of RV were obtained. These targets, such as TLR4, TNF, Interleukin, and CASP3, are involved in many biological processes, such as inflammation, the immune response, and cell proliferation and apoptosis. KEGG enrichment analysis indicated that the TLR signaling pathway was a significant pathway of puerarin against RV. Moreover, puerarin not only had anti-RV effects, but also exhibited therapeutic effects on hepatitis B, measles, hepatitis C, influenza A, and other viral infections, demonstrating its broad-spectrum antiviral effects. As an emerging technology, network pharmacology has been widely used in the research of drug action mechanism, new drug development and other fields, but there are still some problems, such as weak function of database software, high cost of database development and maintenance, error in target prediction and need to be verified by experiment. Therefore, we carried out subsequent experimental verification.

As pattern-recognition receptors, TLRs are the first line of defense against pathogenic microorganisms (32). When 
pathogens invade the human immune system, TLRs can specifically recognize the related molecules that disrupt the immune balance, trigger the host immune response, and establish a barrier against the invasion of pathogens (33). The TLR signaling pathway triggers a signal cascade reaction via interaction with at least five different adaptor proteins (including MyD88 and TRIF), thus producing a variety of pro-inflammatory cytokines and immune regulatory factors $(34,35)$. At least 10 functional TLRs (TLR1-TLR10) have been identified in humans (36). TLR4 is overexpressed or abnormally activated by binding to viral ligands, which ultimately leads intestinal epithelial cells and immune cells to produce a large number of proinflammatory molecules, such as chemokines, interferons, and interleukins (37). The TLR4 mRNA levels in the small intestines of $\mathrm{RV}$-infected neonatal rats have been shown to be significantly higher than those of TLR3, TLR5, TLR7, and TLR9 (33). In addition, the expression of the TLR4 mRNA increases in a time-dependent manner in RVinfected HT-29 cells (38).

MyD88 is a key part of the innate immune response that limits RV infection and diarrhea, which plays a crucial role in the initial stage of RV infection (39). The overexpression of TLR4 activates MyD88, MyD88 continues to conduct the signal downward, leading to the activation of NF- $\mathrm{KB}$ and the synthesis and release of inflammatory cytokines, thus inducing the inflammatory process of the organism $(40,41)$. When MyD88 is knocked out, the infectivity of $\mathrm{RV}$ is enhanced, the transmission of colon and blood is accelerated, which aggravates the diarrhea symptoms of mice-infected RV (39). TRAF6 is a ubiquitin ligase, which is essential in NF- $\mathrm{KB}$ activation downstream of TLRs (42), and is a key adapter molecule linking MyD88 and NF- $\mathrm{KB}$. When TRAF6 is activated, the inflammation cascade is also activated, causing the release of substantial inflammatory factors (such as IL-1 $\beta$, IL-6, and TNF- $\alpha$ ), which lead to tissue damage and organ dysfunction $(43,44)$. In a previous study, the expression of the mRNA and protein of TLR4, MyD88, and TRAF6 was shown to increase significantly in the colon tissue of RV-infected suckling mice (45). Therefore, it is necessary to effectively disrupt the TRAF6mediated cascade reaction to alleviate the inflammatory response caused by RV infection.

$\mathrm{NF}-\kappa \mathrm{B}$ could be activated by multiple families of viruses, including the dsRNA virus. Generally, NF- $\mathrm{kB}$ is inactive in the cytoplasm by binding to Inhibitor of nuclear factor kappa B (IкB). After viral invasion, IкB kinase leads to the release of NF- $\kappa B$ dimers (46). The dimer NF- $\kappa B$ enters the nucleus in phosphorylated form, thereby further regulating the immune and inflammatory responses and protecting the host from viral invasion (47). P65 is one of the most transcriptionally active dimers in the NF$\kappa \mathrm{B}$ transcription factor family (48). The transcriptional activation domain, which is necessary to actively regulate gene expression, only exists in phosphorylated p65 (49). Inhibition of p65 phosphorylation can negatively regulate $\mathrm{NF}-\kappa \mathrm{B}$ activation, thereby inhibiting the host inflammatory response. Similar to the above studies, the mRNA and protein expression of TLR4, MyD88, and TRAF6 in RVinfected cells significantly increased in our study. However, the upregulation effect was markedly reversed by different concentrations of puerarin for $24 \mathrm{~h}$. In addition, puerarin could effectively reduce the overexpression of $\mathrm{p}-\mathrm{p} 65$ protein induced by RV infection.

A significant and almost universal early innate response of receptor cells to viral infection is the release of IFNs, which play a key role in viral clearance and limiting transmission (50). Previous studies have shown that when $\mathrm{RV}$ invades, IFNs are triggered by the induction of viral dsRNA or the stimulation of receptors in nearby infected cells. However, RV can inhibit the immune response of IFNs through different mechanisms, so the ability of endogenous IFNs to restrict RV replication is insufficient (51). IFN- $\gamma$ is the only IFN-II with antiviral activity. Previous studies have shown that IFN- $\gamma$ specifically induced by HRV is mainly present in the ileum of HRV-infected Gn pigs. When VirHRV attacked, the degree of diarrhea of Gn pigs was negatively correlated with the IFN- $\gamma$ produced in the intestine, suggesting the protective immune effect of IFN- $\gamma(52)$. We found that when the Caco- 2 cells infected with $\mathrm{RV}$ were treated with puerarin, the level of IFN- $\gamma$ increased significantly, indicating that puerarin induced an increase in IFN- $\gamma$ and exerted an antiviral effect. The inflammatory response is the most crucial defense mechanism of a host to viruses and other pathogens. The overexpression of pro-inflammatory factors such as IL-6, IL- $1 \beta$, and TNF- $\alpha$ is often related to the activation of NF$\kappa \mathrm{B}$ during viral replication (53). A previous study showed that the peak levels of IL-6 and TNF- $\alpha$ in the sera of RVinfected piglets were essentially coincident with the peak diarrhea scores, and the level of IL-6 increased 1.5-8 times in the early stage (54). Also, the level of the TNF- $\alpha$ mRNA have been shown to increase significantly in the small intestines and spleens of piglets inoculated with RV (55). Fermented Pueraria lobata extract reduces the levels of IL-1 $\beta$, TNF- $\alpha$, and IL- 6 , and restores the gastrointestinal barrier 
function in mice (56). Therefore, we studied the effect of puerarin on the expression of inflammatory factors in RVinfected cells. The results revealed that the levels of IL6 , IL- $1 \beta$, and IFN- $\gamma$ in the RV Wa-infected Caco- 2 cells increased significantly. After treatment with puerarin, the levels of TNF- $\alpha$, IL-1 $\beta$, and IL-6 obviously decreased, while the level of IFN- $\gamma$ further increased. We inferred that the anti-RV effect of puerarin might be related to the inhibition of the TLR4/NF- $\mathrm{BB}$ signaling pathway, thereby reducing the levels of inflammatory factors and increasing the level of interferon.

\section{Conclusions}

In summary, our results indicated that puerarin exerted an anti-RV effect mainly by inhibiting viral replication and proliferation. In addition, puerarin could modulate the inflammatory response induced by RV via the TLR4/NF$\kappa \mathrm{B}$ signaling pathway. Although these findings cannot fully explain the mechanism of puerarin on RV, they provide a basis for further research. This study reveals the potential of puerarin in the treatment of RV infection, suggesting that it might be a promising therapeutic agent.

\section{Acknowledgments}

We would like to thank the support from the Youth research and innovation team of Shandong University of Traditional Chinese Medicine.

Funding: This study was supported by the National Natural Science Foundation of China (No. 81704038, 81904128); the Natural Science Foundation of Shandong Province, China (No. ZR2020MH355); the Post-doctoral Innovation Plan of Shandong Province, China (No. 202003069).

\section{Footnote}

Reporting Checklist: The authors have completed the MDAR reporting checklist. Available at https://dx.doi. org/10.21037/atm-21-6089

Data Sharing Statement: Available at https://dx.doi. org/10.21037/atm-21-6089

Conflicts of Interest: All authors have completed the ICMJE uniform disclosure form (available at https://dx.doi. org/10.21037/atm-21-6089). The authors have no conflicts of interest to declare.
Ethical Statement: The authors are accountable for all aspects of the work in ensuring that questions related to the accuracy or integrity of any part of the work are appropriately investigated and resolved.

Open Access Statement: This is an Open Access article distributed in accordance with the Creative Commons Attribution-NonCommercial-NoDerivs 4.0 International License (CC BY-NC-ND 4.0), which permits the noncommercial replication and distribution of the article with the strict proviso that no changes or edits are made and the original work is properly cited (including links to both the formal publication through the relevant DOI and the license). See: https://creativecommons.org/licenses/by-nc-nd/4.0/.

\section{References}

1. Gómez-Rial J, Rivero-Calle I, Salas A, et al. Rotavirus and autoimmunity. J Infect 2020;81:183-9.

2. Luchs A, Timenetsky Mdo C. Group A rotavirus gastroenteritis: post-vaccine era, genotypes and zoonotic transmission. Einstein (Sao Paulo) 2016;14:278-87.

3. Tacharoenmuang R, Komoto S, Guntapong R, et al. High prevalence of equine-like G3P8 rotavirus in children and adults with acute gastroenteritis in Thailand. J Med Virol 2020;92:174-86.

4. Tarris G, de Rougemont A, Charkaoui M, et al. Enteric Viruses and Inflammatory Bowel Disease. Viruses 2021;13:104.

5. Aliabadi N, Antoni S, Mwenda JM, et al. Global impact of rotavirus vaccine introduction on rotavirus hospitalisations among children under 5 years of age, 2008-16: findings from the Global Rotavirus Surveillance Network. Lancet Glob Health 2019;7:e893-903.

6. Kawase M, Hoshina T, Yoneda T, et al. The changes of the epidemiology and clinical characteristics of rotavirus gastroenteritis-associated convulsion after the introduction of rotavirus vaccine. J Infect Chemother 2020;26:206-10.

7. Leino T, Baum U, Scott $P$, et al. Impact of five years of rotavirus vaccination in Finland - And the associated cost savings in secondary healthcare. Vaccine 2017;35:5611-7.

8. Posovszky C, Buderus S, Classen M, et al. Acute Infectious Gastroenteritis in Infancy and Childhood. Dtsch Arztebl Int 2020;117:615-24.

9. Parashar UD, Nelson EA, Kang G. Diagnosis, management, and prevention of rotavirus gastroenteritis in children. BMJ 2013;347:f7204.

10. Sarker SA, Jäkel M, Sultana S, et al. Anti-rotavirus protein 
reduces stool output in infants with diarrhea: a randomized placebo-controlled trial. Gastroenterology 2013;145:740748.e8.

11. Wu Y, Li Y, Ruan Z, et al. Puerarin Rebuilding the Mucus Layer and Regulating Mucin-Utilizing Bacteria to Relieve Ulcerative Colitis. J Agric Food Chem 2020;68:11402-11.

12. Li M, Yuan D, Liu Y, et al. Dietary Puerarin Supplementation Alleviates Oxidative Stress in the Small Intestines of Diquat-Challenged Piglets. Animals (Basel) 2020;10:631.

13. He L, Wang T, Chen BW, et al. Puerarin inhibits apoptosis and inflammation in myocardial cells via PPAR $\alpha$ expression in rats with chronic heart failure. Exp Ther Med 2019;18:3347-56.

14. $\mathrm{Xu} \mathrm{H}, \mathrm{Hu} \mathrm{M}$, Liu M, et al. Nano-puerarin regulates tumor microenvironment and facilitates chemo- and immunotherapy in murine triple negative breast cancer model. Biomaterials 2020;235:119769.

15. Huang H, Liao D, Zhou G, et al. Antiviral activities of resveratrol against rotavirus in vitro and in vivo. Phytomedicine 2020;77:153230.

16. Wu M, Zhang Q, Yi D, et al. Quantitative Proteomic Analysis Reveals Antiviral and Anti-inflammatory Effects of Puerarin in Piglets Infected With Porcine Epidemic Diarrhea Virus. Front Immunol 2020;11:169.

17. Kibble M, Saarinen N, Tang J, et al. Network pharmacology applications to map the unexplored target space and therapeutic potential of natural products. Nat Prod Rep 2015;32:1249-66.

18. Mosmann T. Rapid colorimetric assay for cellular growth and survival: application to proliferation and cytotoxicity assays. J Immunol Methods 1983;65:55-63.

19. Ma Q, Huang W, Zhao J, et al. Liu Shen Wan inhibits influenza a virus and excessive virus-induced inflammatory response via suppression of TLR4/NF- $\mathrm{KB}$ signaling pathway in vitro and in vivo. $\mathrm{J}$ Ethnopharmacol 2020;252:112584.

20. Wang Y, Bryant SH, Cheng T, et al. PubChem BioAssay: 2017 update. Nucleic Acids Res 2017;45:D955-63.

21. Amberger JS, Bocchini CA, Schiettecatte F, et al. OMIM. org: Online Mendelian Inheritance in Man (OMIM®), an online catalog of human genes and genetic disorders. Nucleic Acids Res 2015;43:D789-98.

22. UniProt Consortium. UniProt: a worldwide hub of protein knowledge. Nucleic Acids Res 2019;47:D506-15.

23. Szklarczyk D, Gable AL, Lyon D, et al. STRING v11: protein-protein association networks with increased coverage, supporting functional discovery in genome- wide experimental datasets. Nucleic Acids Res 2019; 47:D607-13.

24. Otasek D, Morris JH, Bouças J, et al. Cytoscape Automation: empowering workflow-based network analysis. Genome Biol 2019;20:185.

25. Huang da W, Sherman BT, Lempicki RA. Systematic and integrative analysis of large gene lists using DAVID bioinformatics resources. Nat Protoc 2009;4:44-57.

26. Vlasova AN, Shao L, Kandasamy S, et al. Escherichia coli Nissle 1917 protects gnotobiotic pigs against human rotavirus by modulating $\mathrm{pDC}$ and $\mathrm{NK}$-cell responses. Eur J Immunol 2016;46:2426-37.

27. Guo Y, Candelero-Rueda RA, Saif LJ, et al. Infection of porcine small intestinal enteroids with human and pig rotavirus A strains reveals contrasting roles for histo-blood group antigens and terminal sialic acids. PLoS Pathog 2021;17:e1009237.

28. Munlela B, João ED, Donato CM, et al. Whole Genome Characterization and Evolutionary Analysis of G1P8 Rotavirus A Strains during the Pre- and Post-Vaccine Periods in Mozambique (2012-2017). Pathogens 2020;9:1026.

29. Novikova NA, Sashina TA, Epifanova NV, et al. Longterm monitoring of $\mathrm{G} 1 \mathrm{P}[8]$ rotaviruses circulating without vaccine pressure in Nizhny Novgorod, Russia, 1984-2019. Arch Virol 2020;165:865-75.

30. Rojas M, Dias HG, Gonçalves JLS, et al. Genetic diversity and zoonotic potential of rotavirus A strains in the southern Andean highlands, Peru. Transbound Emerg Dis 2019;66:1718-26.

31. Patton JT. Rotavirus diversity and evolution in the postvaccine world. Discov Med 2012;13:85-97.

32. Hagbom M, De Faria FM, Winberg ME, et al. Neurotrophic Factors Protect the Intestinal Barrier from Rotavirus Insult in Mice. mBio 2020;11:02834-19.

33. Azagra-Boronat I, Massot-Cladera M, Knipping K, et al. Oligosaccharides Modulate Rotavirus-Associated Dysbiosis and TLR Gene Expression in Neonatal Rats. Cells 2019;8:876.

34. Hurst J, von Landenberg P. Toll-like receptors and autoimmunity. Autoimmun Rev 2008;7:204-8.

35. Cario E. Toll-like receptors in inflammatory bowel diseases: a decade later. Inflamm Bowel Dis 2010;16:1583-97.

36. Vijay K. Toll-like receptors in immunity and inflammatory diseases: Past, present, and future. Int Immunopharmacol 2018;59:391-412.

37. Gay NJ, Symmons MF, Gangloff M, et al. Assembly and localization of Toll-like receptor signalling complexes. Nat 
Rev Immunol 2014;14:546-58.

38. Xu J, Yang Y, Wang C, et al. Rotavirus and coxsackievirus infection activated different profiles of toll-like receptors and chemokines in intestinal epithelial cells. Inflamm Res 2009;58:585-92.

39. Uchiyama R, Chassaing B, Zhang B, et al. MyD88mediated TLR signaling protects against acute rotavirus infection while inflammasome cytokines direct $\mathrm{Ab}$ response. Innate Immun 2015;21:416-28.

40. Ciesielska A, Matyjek M, Kwiatkowska K. TLR4 and CD14 trafficking and its influence on LPS-induced proinflammatory signaling. Cell Mol Life Sci 2021; 78:1233-61.

41. Li C, Ai G, Wang Y, et al. Oxyberberine, a novel gut microbiota-mediated metabolite of berberine, possesses superior anti-colitis effect: Impact on intestinal epithelial barrier, gut microbiota profile and TLR4-MyD88-NF-кB pathway. Pharmacol Res 2020;152:104603.

42. He X, Zheng Y, Liu S, et al. MiR-146a protects small intestine against ischemia/reperfusion injury by downregulating TLR4/TRAF6/NF- $\mathrm{B}$ pathway. J Cell Physiol 2018;233:2476-88.

43. Hu L, Xu J, Xie X, et al. Oligomerization-primed coiledcoil domain interaction with Ubc13 confers processivity to TRAF6 ubiquitin ligase activity. Nat Commun 2017;8:814.

44. Roh KH, Lee Y, Yoon JH, et al. TRAF6-mediated ubiquitination of MST1/STK4 attenuates the TLR4-NF$\kappa \mathrm{B}$ signaling pathway in macrophages. Cell Mol Life Sci 2021;78:2315-28.

45. Chen X, Liu L, Chen W, et al. Ziyuglycoside II Inhibits Rotavirus Induced Diarrhea Possibly via TLR4/NF- $\kappa \mathrm{B}$ Pathways. Biol Pharm Bull 2020;43:932-7.

46. Zhang W, Zhang R, Wang T, et al. Selenium inhibits LPSinduced pro-inflammatory gene expression by modulating MAPK and NF- $\kappa \mathrm{B}$ signaling pathways in mouse mammary epithelial cells in primary culture. Inflammation

Cite this article as: Chen T, Lin Y, Cao Z, Xue Y, Wang W, Wang X. Network pharmacology analysis and experimental study strategy reveals the potential mechanism of puerarin against rotavirus. Ann Transl Med 2022;10(1):14. doi: 10.21037/ atm-21-6089
2014;37:478-85.

47. Oeckinghaus A, Hayden MS, Ghosh S. Crosstalk in NF$\kappa \mathrm{B}$ signaling pathways. Nat Immunol 2011;12:695-708.

48. Dorrington MG, Fraser IDC. NF-кB Signaling in Macrophages: Dynamics, Crosstalk, and Signal Integration. Front Immunol 2019;10:705.

49. Hayden MS, Ghosh S. Shared principles in NF-kappaB signaling. Cell 2008;132:344-62.

50. Villena J, Vizoso-Pinto MG, Kitazawa H. Intestinal Innate Antiviral Immunity and Immunobiotics: Beneficial Effects against Rotavirus Infection. Front Immunol 2016;7:563.

51. Sherry B. Rotavirus and reovirus modulation of the interferon response. J Interferon Cytokine Res 2009;29:559-67.

52. Yuan L, Wen K, Azevedo MS, et al. Virus-specific intestinal IFN-gamma producing $\mathrm{T}$ cell responses induced by human rotavirus infection and vaccines are correlated with protection against rotavirus diarrhea in gnotobiotic pigs. Vaccine 2008;26:3322-31.

53. Zhang Q, Yu K, Cao Y, et al. miR-125b promotes the $\mathrm{NF}-\kappa \mathrm{B}-$ mediated inflammatory response in NAFLD via directly targeting TNFAIP3. Life Sci 2021;270:119071.

54. Kim JH, Kim K, Kim W. Genipin inhibits rotavirusinduced diarrhea by suppressing viral replication and regulating inflammatory responses. Sci Rep 2020;10:15836.

55. Alfajaro MM, Kim HJ, Park JG, et al. Anti-rotaviral effects of Glycyrrhiza uralensis extract in piglets with rotavirus diarrhea. Virol J 2012;9:310.

56. Choi S, Woo JK, Jang YS, et al. Fermented Pueraria Lobata extract ameliorates dextran sulfate sodiuminduced colitis by reducing pro-inflammatory cytokines and recovering intestinal barrier function. Lab Anim Res 2016;32:151-9.

(English Language Editor: A. Kassem) 